\title{
Features of Students Training: Qualifications and Technology
}

\author{
V. Vasyukov, I. Mozhaeva, A. Peretolchin, M. Kryuchenko, O. Kubanov
}

\begin{abstract}
The article is based on the study of technologies and recommendations developed by the authors as a result of the experience accumulated in teaching a set of disciplines aimed at gaining knowledge and skills in the field of investigating certain types of crimes, performed at the Department of Investigation of the Lukyanov Orel Law Institute of the Ministry of the Interior of Russia from 2010 to 2019. The article examines the issues of preparation and selection of the most optimal training model, and the applied part provides the algorithm of a lesson, as well as options for assessing the work done by teams.
\end{abstract}

Keywords: algorithm, education, educational process, investigation, technology.

\section{INTRODUCTION}

The objective need to prepare legal specialists for certain types of investigative activities requires compliance with additional requirements for the content of disciplines and specialized courses of educational organizations, the main of which is the applied focus of the training process. The applied nature of the disciplines gives students a real opportunity to learn specific knowledge and to handle the amount of received information in a correct, flexible and dynamic way. The content of the actual material to be studied in the framework of a particular academic discipline is largely predetermined by its subject, that is, by the circle of objects, phenomena, and processes, for the study and scientific explanation of which this discipline exists [1].

According to the dogmatic expression of the famous lawyer Strogovich, the investigation of a criminal case can and should lead to a morally valuable result, but in some cases, with the wrong approach of an investigator, it can cause serious moral harm to the individual and society [2].

In the current socio-economic situation, updating the internal subjective potential of a person becomes a leading

Revised Manuscript Received on December 30, 2019.

* Correspondence Author

V. Vasyukov*, Moscow State Institute of International Relations (University), Moscow, Russia; Orel Law Institute of the Ministry of Internal Affairs of Russia named after V. V. Lukyanov, Orel, Russia.

I. Mozhaeva, Research Center, Academy of Management of the Ministry of Internal Affairs of the Russia, Moscow, Russia.

A. Peretolchin, East-Siberian Institute of the Ministry of Internal Affairs of Russia, Irkutsk, Russia.

M. Kryuchenko, Academy of Management of the Ministry of Internal Affairs of the Russia, Moscow, Russia.

O. Kubanov, Academy of Management of the Ministry of Internal Affairs of the Russia, Moscow, Russia.

(C) The Authors. Published by Blue Eyes Intelligence Engineering and Sciences Publication (BEIESP). This is an open access article under the CC BY-NC-ND license (http://creativecommons.org/licenses/by-nc-nd/4.0/) factor in his or her development, as well as the progressive development of society and culture. If the preparation of people for mobility and uncertainty is recognized as one of the guidelines of modern professional education, it is necessary to build a chain of technological actions aimed at achieving the goal.

Activation of a social position, the ability to respond to the challenges of social change, the ability to make decisions in nonstandard situations, tolerance of other people's opinions, the ability to interact with colleagues, to engage in dialogue this is a component in higher education that is solved precisely in the unit of social and humanitarian education.

Preparing investigators for mobility and the uncertainty of the formation of certain official situations requires teachers to teach their students to make the right choice based on an appropriate legal assessment. A modern investigator should be directed not only to cognitive activity but also to considering complex interdisciplinary problems as integral phenomena, to setting goals based on a comparison of professional and personal priorities and developing the most tactically effective work algorithm.

In assessing the actions of a police officer in solving a situation, teachers should take into account, inter alia, communication skills (both with a partner and with an "opponent"), tactics of actions, the correct use of coercive means, and the legality of all measures, taken to achieve the goal (solving the situation) [3].

As it is noted in some studies, after graduation, specialists-beginners (teachers) experience a "shock of reality" [4] or "practical shock" [5], when they first encounter problems in practical activities. This is due to the fact that, in most cases, theoretical segments are taught at humanitarian universities in isolation from practice [6], [7], [8].

Thus, in response to the diverse demands placed on the work of the $21^{\text {st }}$ century police force and the growing emphasis on the philosophy of public security police, the Los Angeles Police Department has made changes to its training programs and teaching methods at the Academy, including the use of officer training concepts, models of solving the problems of the community police, known as Clients, Analyzing and Acquiring Information, Partnerships, Response, Assessment (CAPRA), and the use of training-based scripts and simulation activities [9].

These problems are fully correlated when creating conditions for the development of multilevel training of police personnel with higher professional education in accordance with the federal state educational standards.

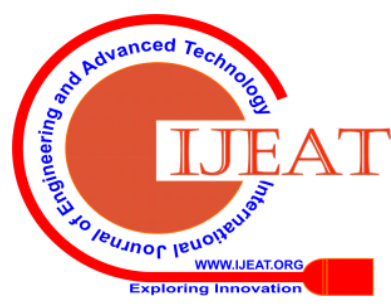




\section{PROPOSED METHODOLOGY}

\section{A. General Description}

The sources for writing this article were the materials from journal publications, dissertations, and study guides. The study used the basic methods of cognition: analysis, observation, evaluation, modeling, the systemic and comparative method. The method of analysis made it possible to differentiate the structure of crime investigation methods into certain segments, to determine the main priorities of the study, and to elaborate the necessary algorithms.

\section{B. Algorithm}

The model of a lesson, consisting of the following algorithm, is the most effective:

1. Checking the personnel of the group. A teacher solves organizational issues (receives a report from the group commander, identifies those who are absent, makes corresponding entries in the journal). During the implementation of this element of the introductory part of the lesson, the attention should be paid to the composition of the study group, whether there are formal and informal leaders, as well as the most trained students (according to a teacher). In the process of forming teams, this fact can be significant.

2. Introduction by a teacher. The introduction by a teacher should include such elements as setting goals and objectives of the lesson.

\section{Testing using the Votum hardware and software complex.}

The Votum system is an interactive system of training, testing, and voting. During the classes, students are given remote controls with which they answer test questions or can say a few words during the discussion. Thus, the Votum system provides interactive communication in the process of knowledge control, conducting questionnaires, educational games, and other activities.

To work with the system, one computer is required, on which the Votum software is installed. A radio receiver is connected to the computer via the USB port (Fig. 1).

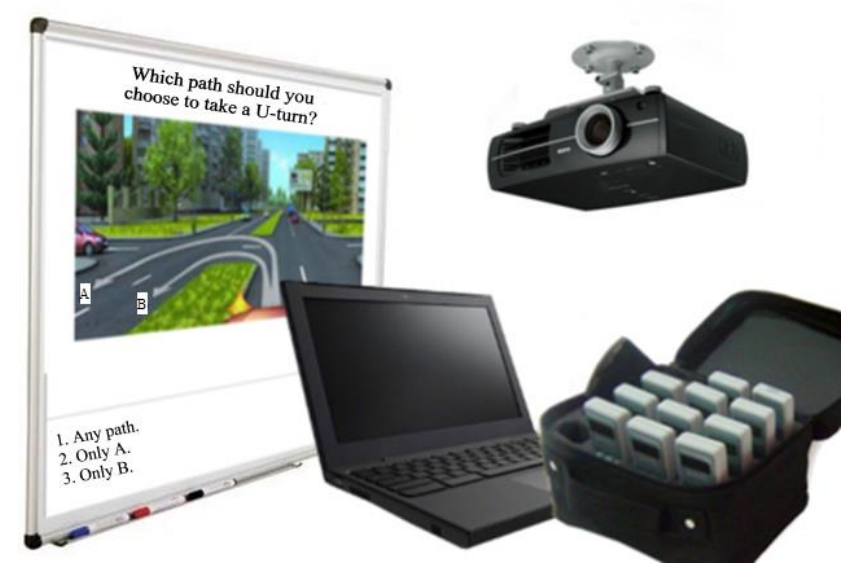

Fig. 1. Elements of the Votum system

The principle of operation. The students are given wireless remote controls. With their help, they answer questions by choosing the correct answer from several options or typing the answer on the remote control. In the same way, they can let the teacher know that they have questions. The signals from the remote controls come to the computer through the radio receiver, are processed by the program, after which the Votum instantly gives the results (Fig. 2).

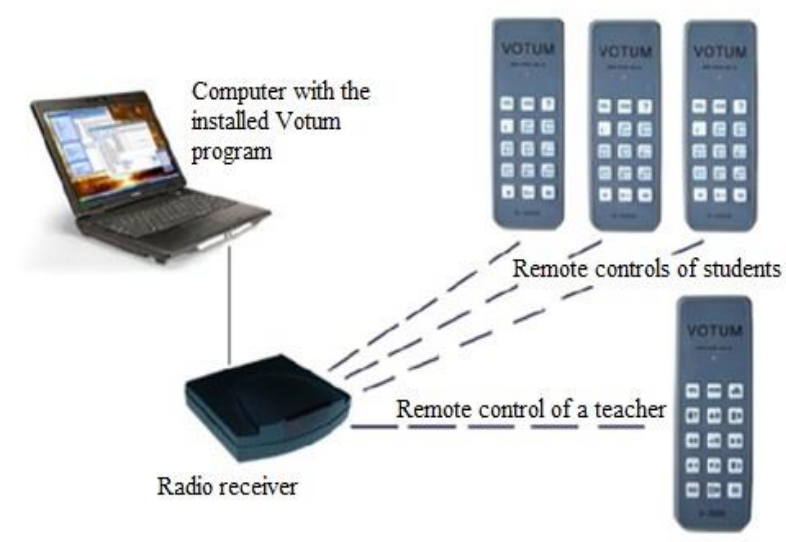

Fig. 2. The principle of operation of the Votum system

The teacher controls the testing process using his or her remote control. Tests are created using the Votum built-in editor program, as well as using MS PowerPoint.

Thus, this interactive system is a powerful and convenient tool for improving the effectiveness of the educational and managerial process.

4. The division of the study group into three teams.

In the classroom, working places are formed for teams. As the practice shows, the most convenient is the T-shaped and L-shaped arrangement of places in the classroom, formed from desks.

The main feature of the formation of these teams is selecting students from the study group according to the alphabetical list in the journal. At the same time, the managerial link (leaders), as well as the roles of a representative from each team, are determined by students independently, based on personal abilities.

Each team should determine the person at the appointed time, who will be endowed with the functions of the following officers (roles):

1) Investigator No. 1 - submits a report based on the results of the inspection of the crime scene, qualifies the offense, and makes a decision to institute criminal proceedings;

2) Investigator No. 2 - submits a protocol for obtaining samples for a comparative study, a decision on the appointment of forensic examinations, the necessary notifications;

3) Specialist No. 1 - carries out video filming, registers a made copy of the video recording as an attachment;

4) Specialist No. 2 - identifies, records, removes traces, takes photographs, prepares an illustration table with an electronic copy of the photographic survey;

5) Criminal investigator No. 1 - receives explanations, makes a report on the detection of evidence of a crime, a report on the work done by the operational investigative group (hereinafter - OIG), assists the investigator and the specialists;

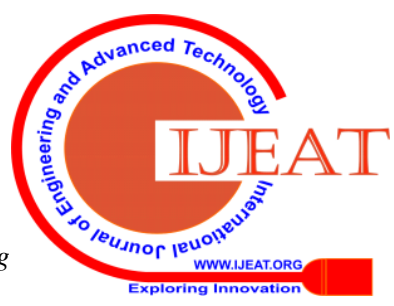


6) Criminal investigator No. 2 - receives explanations, draws up a protocol of accepting an oral application, a report on the work done by the OIG, assists the investigator and the specialists;

7) a suspected person - gives explanations, makes an acknowledgment of guilt in writing, makes 4 requests - IC, place of residence, place of work, psychoneurological dispensary/narcological dispensary;

8) an applicant - gives explanations, makes a scheme for the inspection of the crime scene, draws up an inventory of the materials of the preliminary check of the reported crime.

9) an eyewitness - gives explanations, draws up a diagram of the inspection of the crime scene, sews materials on the machine for preliminary checks of the reported crime.

\section{Work of the team with the model of a crime.}

Each team is given a specific, problematic, and typical investigative situation in the form of a model, the solution of which is assigned to the students. The organizational role of a teacher is reduced to the overall coordination of the groups. A teacher cannot intervene in the procedural and tactical activities of the team. At the same time, a teacher can, depending on the conditions of the model, play the role of an internal affairs officer on duty, the head of the investigative body, the prosecutor, etc.

The decision of a certain model, expressed by the complex of circumstances of a specific criminal act, occurs in three stages:

5.1. Analysis of the presented situation, determination of means to achieve the goal. In the examined practical lesson, such means are investigative and procedural actions.

5.2. Distribution of provided time. A teacher also does not intervene in this process, with the exception of determining the time of the inspection of the crime scene. As the practice of teaching six-hour classes has shown, it is most advisable to start the inspection of the scene using a forensic training polygon from the second double lesson of the training sessions (10.35 a.m.). This is due to the fact that the activities of the operational investigative group during the inspection of the scene should not be interrupted. Therefore, it is advisable not to make the time of the inspection coincide with the time interval between the first and second or second and third double lesson. As a rule, the teams have time to inspect the scene of the incident in one double lesson and after it, they have time for a break (12.05 a.m.). The remaining time 70 minutes of the first double lesson and 60 minutes of the third double lesson - the teams distribute at their discretion (see Table I).

5.3. The solution of the presented crime model. Teamwork is the central place in the model, as it is the most effective method of learning and sharing information.

The team's working methods are attractive for the student's independent work when receiving information and analyzing it, bringing it into a logical system, analyzing its flexibility, and the possibility of applying various forms of training.

It is within the framework of teamwork that the situations are analyzed as a set of circumstances, conditions or situations in which students find problems.

The students listen to each other, speak for themselves, write down, analyze the result; at the same time, they argue, learn to listen, agree with the best approach to solving a problem, find errors, design solutions, actions, and prepare procedural documents for a common layout.

For effective teamwork, the following rules are observed: -common character of the problem for everyone;

-common character of requirements;

-the number of people in the group should not exceed eight (for the effective work of each person);

-highlighting the leader (formal or informal);

-transparency of work in all groups and collective discussion;

- taking into account the capabilities of the group when posing the problem (tasks should be feasible).

The fulfillment of these rules makes it possible to organize a developing educational process, since in solving a creative problem, students first mentally sort out the methods of solution they know and, not finding it in the arsenal of their previous experience, construct a new method.

6. Analysis of the work of teams with the model. The work of each team should be analyzed by two teachers and the consultant who supervised it. In this case, the opinion of other consultants, who may also submit their observations, should be taken into account. This is recommended to be done during the work of teams, but in a separate room.

7. Verification of materials and performance evaluation. At the end of the work, the teams submit materials, prepared within the framework of the model, to the consultants. The task of the consultants is to point out errors of a procedural, forensic and technical nature (spelling, punctuation, compliance with the rules of workflow, etc.). In turn, the teachers announce the results of analyzing group work of the teams, which were obtained earlier during the discussion. After the examination, the practitioners pass the materials to the teachers, who recheck them. At the same time, all consultants alternately express their views on the work of each team.

8. Summarizing the lesson. At this stage, the key points of the work done by students and practitioners should be summarized briefly, they should be thanked for their fruitful work, and the incentives for attracting practitioners to classes should be identified.

9. Putting marks of the students in the gradebook. Three marks are given to the students in the gradebook: 1) according to the results of the test using the Votum system; 2) based on the results of work in groups; 3 ) based on the results of the submitted documents.

10. Announcing a self-study assignment. The teacher provides a list of normative acts and methodological recommendations, which the students should get acquainted with before the next lesson.

\section{Flow Chart}

Published By: 
Table - I: Segmentation of a lesson using the developed algorithm

\begin{tabular}{|c|c|c|}
\hline \multicolumn{3}{|c|}{$\begin{array}{c}\text { DISTRIBUTION OF WORKING TIME AND FUNCTIONS OF } \\
\text { TEACHERS DURING THE LESSON }\end{array}$} \\
\hline Time & $\begin{array}{c}\text { Teacher } 1 \\
\end{array}$ & Teacher 2 \\
\hline $08.50-08.55$ & $\begin{array}{l}\text { Checking the presence of } \\
\text { the personnel of the } \\
\text { group. } \\
\text { Setting goals, objectives, } \\
\text { the relevance of the } \\
\text { lesson, explanation of its } \\
\text { order }\end{array}$ & $\begin{array}{l}\text { Preparation of the Votum } \\
\text { hardware and software } \\
\text { complex for the test. }\end{array}$ \\
\hline 08.55-09.05 & $\begin{array}{l}\text { Preparation of didactic } \\
\text { material, verification of } \\
\text { the readiness of forensic } \\
\text { equipment. }\end{array}$ & $\begin{array}{l}\text { Testing using the Votum } \\
\text { hardware and software } \\
\text { complex. }\end{array}$ \\
\hline 09.05-09.15 & $\begin{array}{l}\text { Designation of the } \\
\text { composition of the } \\
\text { groups. }\end{array}$ & $\begin{array}{l}\text { Presentation of models and } \\
\text { didactic materials. }\end{array}$ \\
\hline $09.15-09.25$ & Work with groups. & Checking the test tasks. \\
\hline $09.25-10.20$ & Work with groups. & Work with groups. \\
\hline $10.20-10.35$ & $\begin{array}{l}\text { Final preparation of } \\
\text { forensic training } \\
\text { polygons for the } \\
\text { inspection of the scene. }\end{array}$ & $\begin{array}{l}\text { Meeting and escorting } \\
\text { consultants (practitioners) to } \\
\text { the classroom. }\end{array}$ \\
\hline $10.35-12.05$ & $\begin{array}{l}\text { General coordination of } \\
\text { groups during the } \\
\text { inspection of the scene. }\end{array}$ & $\begin{array}{l}\text { Explaining their functions to } \\
\text { consultants. General } \\
\text { coordination of consultants. }\end{array}$ \\
\hline $12.05-12.20$ & & eak. \\
\hline $12.20-13.20$ & $\begin{array}{r}\text { General coordination } \\
\text { Analysis of t }\end{array}$ & $\begin{array}{l}\text { f groups and consultants. } \\
\text { work of groups. }\end{array}$ \\
\hline $13.20-13.40$ & $\begin{array}{l}\text { Verification of materials } \\
\text { together with consultants. }\end{array}$ & $\begin{array}{l}\text { Announcement of } \\
\text { preliminary results made by } \\
\text { teachers and consultants } \\
\text { during the analysis of work }\end{array}$ \\
\hline $13.40-13.50$ & General su & ary. Assessment. \\
\hline
\end{tabular}

\section{DISCUSSION}

The fundamental principle of the Bologna reforms in higher education is student-centered education, which involves shifting the emphasis of the educational paradigm from the transfer of knowledge by a teacher to learning as an active educational activity [10], which contributes to the positive development of critical thinking [11], problem-solving and decision-making skills of students [12]. Obviously, each police officer should be well trained in accordance with the principles of the practical application of regulatory acts while interacting with citizens, including minors [13].

The teacher is supposed to preserve not only his or her role status (transmitting knowledge) but also higher levels of counseling and motivation for students in the selection of information, its sources, the organization of adequate training situations, and the elimination of identified gaps. The new approach focuses on the results of the learning process, which become the main outcome of the educational process for students in terms of knowledge, understanding, and abilities [14].

The new system of higher professional education is aimed at forming general cultural and professional competencies among students, allowing them to master various types of professional activity in practice.

Conducting training sessions on the basis of modeling specific investigative situations in terms of using a certain algorithm allows students to feel like an investigator, criminal investigator, criminal specialist and, thus, to some extent adapt to the conditions of professional activity. In particular, to acquire the necessary professional skills in organizing the investigation of crimes, conducting investigative and other procedural actions, making procedural decisions, as well as drafting procedural and official documents.

The priority of algorithmization in learning is openness, on the one hand, and rigidity in the efficiency of learning, on the other hand [15]. Concerning the organization of the educational process, this is due to the fact that the teacher and students are both responsible and free in the learning process.

The teacher is responsible for the collection and selection of educational material and the effective organization of its use. He or she is free to choose the most suitable models from many existing ones. Students are responsible for preparing for the lesson and effectively completing the tasks according to the model, although they are free in making the decisions and drawing conclusions as a result of analyzing the investigative situation.

Students may make erroneous decisions, because in an investigative situation they occur under artificially created conditions, in the authors' case, within the boundaries of a forensic multifunctional polygon complex. At the same time, they should be aware of the responsibility for a wrong decision, which in real life can be of crucial importance for the participants of the investigation.

Preparing for classes using the algorithm has certain specifics, since its effectiveness largely depends on the conceptual understanding and motivation of students [16], and requires high-level thinking skills from a teacher [17].

The case method is used in various sources with different terms, such as case work, case method, plan game, simulation game and decision-making game. The inclusion of a certain algorithm in the process of training students contributes to: a) the formation of the ability to solve typical problems in all types of professional activities: organizational, procedural, and tactical; 2) humanization of relationships between participants in the educational process [18]; 3) the formation of the subjective position of students; 5) the development of analytical and evaluative skills, teamwork, finding the most rational solution to the problem [19]; 6) activation of communicative abilities; the development of flexibility, the dialectic nature of thinking [20].Thus, it can be stated that a lesson with the use of technology is an effective means of implementing a competency-based approach in teaching specialized disciplines. To one degree or another, it allows students to form key competencies: personal self-improvement, value-semantic, general and cultural, educational and cognitive, informational, communicative, as well as social and labor competencies.

The case method involves adding several types of analytical activities that are possible when understanding the situation. This requires a high level of methodological culture of a teacher. The methods or actions that a teacher uses as a medium for transferring knowledge, experience or information to participants in order to facilitate their learning can lead to a change in their working behavior and attitude in accordance with the purpose of the examined discipline [21]. 
Case studies are specific training situations, specially developed on the basis of factual material for the purpose of subsequent analysis in training sessions. During the analysis of situations, students learn to act in a "team", conduct analysis and make management decisions. The case-study method or the method of specific situations is a method of active problematic and situational analysis based on training by solving specific problems - situations (solving cases).

The presence of a teacher during the lesson makes it possible to monitor the progress of students and adjust the process if necessary. This is especially beneficial when the content of training is multidisciplinary. The presence of a teacher can also affect students' motivation [22].

Given the purely specific nature of the content of training, the model implementation algorithm assumes the presence of a teacher in order to obtain instant feedback and timely response to the reaction. In the course of the study, it became apparent that the training method in question was most effective when using the role settings of the trainees.

A team is a small group united by some criteria, the attention and intellectual efforts of which are temporarily concentrated by the researcher on a specific topic.

The team method arose at the intersection of a number of research traditions and took a certain place among other methods of empirical sociology. The widespread use of this method in a number of areas is due to some of its unique properties, which are still the subject of discussion and debate. The main essence of this method is that the moderator (the organizer of a specific study) forms a group focused semi-standardized interview in the form of a group discussion according to a previously developed scenario.

The optimal team size ranges from 6 to 9 people. A smaller number of groups makes the results less productive, and the leader has to make more efforts to increase its activity.

The choice of group members is determined by the objectives of the study. The success of the teams depends on the effectiveness of the host. The moderator (interviewer) should skillfully manage the behavior of the group without any gross interference, show interest in the positions and comments of the participants.

At a practical lesson of criminal disciplines, the team should represent a joint group of students from 5 to 9 people, which is created to solve a specific model. In the authors' case, operational investigative groups with the role functions of each participant act as a team. At the same time, a feature of the work of teams with crime models in such forms is that these independent formations can focus on a model of a specific crime. In this regard, it is easier to solve problems that may arise in their practical activities.

This was one of the reasons for attracting investigative officers-practitioners to practical training. As the practice of conducting this kind of training has shown, the participation of investigators, heads of investigative departments is an integral part of forming a comprehensive understanding of the activities of an investigator at the stage of initiating criminal proceedings. Specialists-practitioners should be involved as consultants who can not only give oral instructions to team members or, in the authors' case, members of operational investigative groups but also help to solve a problem situation artificially created by teachers. Moreover, the presence of such participants in business games, on the one hand, disciplines students, on the other hand, provides moral support, given that the experience of a practitioner can contribute to the successful completion of a task.

\section{RESULT ANALYSIS}

The methodology always requires special training from a teacher, since the solution of the assigned tasks is accompanied by the use of a whole range of forces and means, which, as a rule, the student cannot prepare independently. When preparing the practical lesson "The activities of an investigator at the stage of initiating criminal proceedings", it should be borne in mind that by the time this topic is studied, the students already have certain basic knowledge obtained in the course of studying the subjects "Preliminary investigation in the Department of Internal Affairs", "Criminalistics", "Criminal Procedure Law", "Criminal Law", "Psychology", etc. Thus, by the time the lesson is held, students should be able to: correctly qualify a criminal act, have an idea of the means of obtaining information at the stage of checking reports of a crime, to know the procedure for conducting this check, to know the procedure for detecting, recording and seizing traces at the scene of the incident, to have an idea of the forms of expression of the willful decision of an investigator based on the results of the initial investigative and procedural actions.

To implement the set tasks, each team is provided with the following:

a) a workplace with the necessary equipment:

- laptops (as a rule, students use their own);

- a printer (as a rule, a printer from the learning department is used);

- forms of procedural documents in electronic form;

- printed forms of procedural documents;

- photo cameras (1 pc. for each group);

- video cameras (1 pc. for each group);

- specialized investigative suitcases (1 pc. for each group) equipped with, among other things, a compass, fingerprint powders (film), a laser range finder, disposable gloves, etc.;

- packaging material (boxes, test tubes, envelopes, bags, etc.);

- clerical tool for sewing materials.

b) artificially created conditions for the inspection of the scene with a trace "layout". Each group is provided with a separate training polygon with preliminarily prepared traces in accordance with the conditions of the model. At the same time, students need to choose the right tactics for conducting investigative actions in order to exclude the possibility of destroying tools and objects that were used by the violator, as well as to exclude the possibility of hiding other material evidence and other traces of the crime, including preventing or neutralizing any opposition to the ongoing crime investigation.

Thus, when conducting a lesson on the model of "fraud using electronic means of payment" during the inspection of the scene, it is necessary to pay attention to the availability of skimming equipment and the correct sequence of actions for its description and withdrawal.

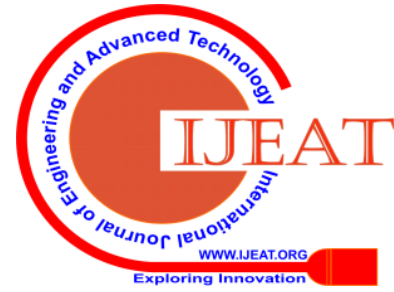
\& Sciences Publication 
When conducting a search of a suspect's house or workplace, special attention should be paid in particular to inspecting a computer and mobile communications, ensuring the safety of existing data and preventing remote access of the criminals to these electronic means in order to destroy and conceal information of interest to the investigation.It should also be noted that while investigating fraud, committed using electronic means of payment, a special role is played by the tactics of conducting interrogations of witnesses and victims. The obtained materials play an important role in qualifying a criminal assault and, subsequently, in deciding on a criminal case. One of the key points for students is the need to establish the fact of fraud or breach of trust in relation to an authorized employee of a credit, trade or other organization.

c) instructed participants in the investigation (suspect, eyewitness, applicant) - from the number of the students who familiarize themselves with the background information before the start of the inspection, during the inspection they direct the operational investigative group, after the examination they are interviewed by team members acting as members of the operational investigative group.

The role of a suspected person should particularly be noted, whose identity should not be known by the beginning of the team's work with the model. In the process of detecting traces and obtaining verbal information from the applicants during the survey, the background data of the suspected person are established by the participants in the operational investigative group.

At this stage, with the advent of this character, the model is complicated by the possibility of alternative actions by team members.

Thus, for example, during one of the practical exercises of the team working with the model "fraud committed in the field of construction of multi-apartment buildings" (this type of fraud is currently taking on new forms in the Russian Federation due to the transition of the construction industry to project financing), during the inspection of the scene by citizens acting as applicants, who suffered from deception and abuse of trust in accordance with the plot, the address of the office was indicated, disclosing the location of the construction organization and the developer. In that place, contracts of equity participation in construction were concluded for the acquisition of ownership of the capital construction object. This place was one of the classrooms on the ground floor of the educational building, conditionally (in advance) designated as the office of the developer. If the criminal investigators sent by the investigator to detain the person acting as the head of the construction organization did not use tactical means to get into the "office", but directly informed the office that they were police officers, or the organization learned somehow about a possible visit by law enforcement officials, the suspected person hid through a window in the area of the sports camp, located next to the educational building.

Thus, the teachers envisaged a number of variable situations when the model could be complicated or, on the contrary, simplified for teams.

This, firstly, contributed to the formation of nonstandard solutions, secondly, significantly enlivened the model, made it more close to reality, and thirdly, forced to use the most tactful and competent approach to the preparation of such events. Given all the simplicity of the named stage, a great skill of a teacher is required to stimulate students' interest in independent and group work, to activate and intensify their educational activities.

When the teams are working with a model, teachers should pay special attention to the discussion, during which the options for solving each situation are presented, and answers to emerging questions and opposition emerge.

d) expert consultants from the number of practitioners, who begin to work from the moment of the "departure" of the operational investigative group to the scene of the incident, that is, from the moment the team works at the training polygon. For each group, its own consultant is determined, who can monitor its work in real time by means of a surveillance camera on the polygon and multimedia equipment with the output of the image of the polygon.

One of the conditions of the model is the possibility of complicating the situation by the fact that the consultant can directly "arrive" at the scene of the incident at an uncertain period of time, that is, come to the training polygon during the team's work as a responsible person from the management and in every way try to transfer managerial functions to himself or herself (such situation is typical in criminal investigations).

After various provocations made at the initiative of the consultant (5-10 minutes should be allocated for this), he or she begins to perform the functions of an expert, that is:

- provides consultations of an organizational nature;

- helps in choosing the most effective algorithm for further teamwork.

However, the consultant should not:

- take on the decision-making initiative;

- carry out the work assigned by the group leader to its members;

- correct mistakes made during the inspection;

- give consultations regarding the correctness of filling out procedural documents, detecting, recording and seizing traces of a crime, choosing tactics, and the correctness of the qualification of a crime.

The maximum period of time for the work of expert consultants when examining the scene is 40 minutes. The remaining time - 50 minutes, while being in the classroom,

he or she analyzes the work of the team, identifies errors, points them to teachers and colleagues.

The following should be particularly highlighted: the teams work independently and may refuse to consult with a practitioner who, after performing provocations,

can be removed from the scene. In addition, teachers cannot in any way influence the course of action. At the same time, teachers should strongly support the provision of additional equipment to the team if such a need arises.

Teachers should make an announcement regarding the completion of the team's work with the model in advance (10-20 minutes in advance). As the practice shows, teams have little time for systematization of materials, their numbering, making inventory and sewing them using a special machine. Meanwhile, as a rule, it takes 10-15 minutes. 
If the team does not make it in the set time, certain penalties should be imposed, which can be expressed in a decrease in points for the group work done. The most optimal penalty formula is the ratio of 1 minute of "delay" to a decrease in the total amount by ten points. As a rule, this serves as an additional motivation for the proper self-organization of the team.

Two criteria are used to evaluate the work according to the results of the team:

- group work (teamwork, ability to manage, carry out assignments, timeliness of execution, discipline);

The teamwork of each team is jointly evaluated by teachers and practitioners. At the same time: the "excellent" mark is given to the team that showed the best organization of work, the correct coordination of actions, the presence of effective management decisions, professional discipline, communication skills, algorithmization of actions; the "satisfactory" mark is given to the group that showed in the work the absence or insufficient fulfillment of the above-mentioned criteria.

- individual work (the correctness of processing procedural documents, work with technical and forensic tools, use of tactics and combinations) is evaluated according to a rating system:

1) a procedural error, an omission (minus 3 points for each error) - the absence of the signature of the participating person, or an element or details in the document, wrong correction, indication of the element.

2) tactical error, omission (minus 3 points for each error) an incorrect sequence of actions, violation of the rules for detection, recording, and seizure of traces.

3) technical error, omission (minus 1 point for each error).

4) an error in the qualification of a crime (minus 30 points) - an incorrect indication of a clause, part, article of the Criminal Code of the Russian Federation in a decision to institute criminal proceedings.

Criteria for evaluation:

- 20 points - "good".

- 30 points - "satisfactory".

- 50 points - "unsatisfactory".

\section{CONCLUSION}

At present, Russia has created the conditions for the development of multilevel training of personnel of higher professional education. However, the requirements for federal state educational standards pose quite a difficult task for a teacher:

- independent formation of educational programs projects by universities based on requirements in accordance with the development of the labor market and the requirements of employers;

-improving the quality control system of the educational process in the context of expanding academic freedoms;

-development of new mechanisms for planning the personnel training process in connection with the transition to a point-rating system for assessing knowledge.

In this regard, the pedagogical potential of the case-study method is much greater than the pedagogical potential of traditional teaching methods. The presence of disputes, discussions, and argumentation in the structure of the case-study method trains the participants in the discussion, teaches compliance with the norms and rules of communication.

A teacher should be sufficiently emotional throughout the entire learning process, resolve and avoid conflicts, create an atmosphere of cooperation and competition at the same time, ensure the observance of the personal rights of students.

The effectiveness of a teacher who implements the case-study method in his or her teaching practice, is associated with the implementation of a number of principles:

- the diversity and effectiveness of the didactic arsenal, which involves the mastery of didactics, its methods and techniques, their targeted use in the educational process;

- partnerships, cooperation with students, based on the recognition of students as partners in educational activities, on interaction and joint discussion of situations;

- shifting the role of a teacher from transmitting and "chewing" knowledge to organizing the process of its extraction, i.e. reducing the role of a teacher as the only "holder" of knowledge, increasing his or her role as an expert and consultant helping a student to navigate in the world of scientific information;

- the principle of absorbing the achievements of pedagogical science, the experience accumulated by colleagues - psychological and pedagogical justification, the formulation of not only educational but also upbringing goals significantly distinguishes a teacher who implements the case-study method from a teacher who uses classical teaching methods;

- the principle of creativity, which involves the transformation of a model and a lesson with its application into a unique creative product - the method significantly expands the space of creativity, covering the activity of creating a model as a unique intellectual product, designing the learning process, improving the teaching technology, involving the student in the work, strengthening the role of creative improvisation during training, etc.

- the principle of pragmatism, focusing on a clear definition of the capabilities of a particular model, planning learning outcomes.

- the points of view of the formation of students' skills in analyzing the situation and developing patterns of behavior in it. As the authors' research on the technology showed, when teaching techniques for investigating certain types of crimes, the role-playing method is the most effective. One of the main advantages of this method is that it provides students with the opportunity to apply content to a simulated situation, thereby gaining the opportunity to practice without specific legal consequences. Role play is particularly well suited to provide students with practical and collective reflection on what to do when reporting a crime, conducting investigative examinations, searches, seizures, and other investigative actions. Role-playing games also contribute to the development of empathy and certain emotional stability [23], [24]. 


\section{REFERENCES}

1. M. E. Bershadsky, "Consultations: goal-setting and competence approach in educational process", Pedagogical technologies, vol. 4 , 2009, pp. 80-89.

2. M. S. Strogovich, Criminal prosecution in the Soviet criminal process. Moskow: USSR Academy of Sciences Publishing House, 1951, pp. 22-23.

3. I. Isaieva, "Police Training in the System of Professional Training for Federal Police Force in Germany", Comparative Professional Pedagogy, vol. 8, 2018, pp. 54-59.

4. S. Veenman, "Perceived problems of beginning teachers", Review of Educational Research, vol. 54, 1984, pp. 143-178.

5. M. A. Flores, and C. Day, "Contexts which shape and reshape new teachers' identities: A multi-perspective study", Teaching and Teacher Education, vol. 22, 2006, pp. 219-232.

6. F. Korthagen, J. Lougran, and T. Russell, "Developing fundamental principles for teacher education programs and practices", Teaching and Teacher Education, vol. 22, 2006, pp. 1020-1041.

7. G. Seferoğlu, "Teacher candidates' reflections on some components of a pre-service English teacher education programme in Turkey", Journal of Education for Teaching, vol. 32(4), 2006, pp. 369-378.

8. H. S. Tülüce, "Using the Case Story Method in a Teacher Education Practicum: Affordances and Constraints", Educational Sciences: Theory and Practice, vol. 16(4), 2016, pp. 1275-1295.

9. L. R. Perry, "Twenty-First Century Police Training: Recruits' Problem-Solving Skills Following Scenario-Based Training". ProQuest LLC, Ph.D. Dissertation. Fuller Theological Seminary, School of Psychology, 2012.

10.M. Bocharnikova, "Competence approach: history, content, problems of realization", Elementary school, vol. 3, 2009, pp. 83-89.

11.M. Cin, Strategies, methods and techniques that can be used in life knowledge and Social Studies. Istanbul: Undergraduate Publishing, 2005, pp. 119-164.

12.M. Bilen, Teaching From Plan To Practice (7. Printing.). Ankara: ANI Yayıncilık, 2006.

13.N. A. Watson, and R. N. Walker, Training Police for Work with Juveniles. International Association of Chiefs of Police. Washington, DC: Office of Juvenile Delinquency and Youth Development (DHEW), 1965.

14.B. K. Lanahan, and E. A. Yeager, "Practicing teachers as elementary social studies methods instructors: Issues in preparing preservice elementary teachers", Social Studies Research and Practice Journal, vol. 3(2), 2008, pp. 10-28.

15.I. Demircioğlu, "Does teaching history in Turkey support Active Citizenship Education? Views Of Turkish History Teachers", in, Education in identity, citizenship and history in the century, M. Saffron, and D. Wish, Eds. Istanbul, Turkey: Yeni Human Publishing House, 2005

16.Y. J. Dori, and O. Herscovitz, "Question-posing Capability as an Alternative Evaluation Method: Analysis of an Environmental Case Study", Journal of Research in Science Teaching, vol. 36(4), 1999, pp. 411-430.

17.D. G. Armstrong, and T. V. Savage, Secondary Education, 2nd ed. New York: Macmillan Publishing Company, 1990.

18. S. Wassermann, Introduction to Case Method Teaching. A Guide to the Galaxy. New York, Columbia University: Teachers College Press, 1994.

19. C. F. Herreid, "Case Studies in Science. A Novel Method of Science Education”, Journal of College Science Teaching, vol. 23 (4), 1994, pp. 221-229.

20. M. C. Herron, and K. M. Quinn, "A Careful Look at Modern Case Selection Methods", Sociological Methods \& Research, vol. 45(3), 2016 pp. 458-492.

21. W. Ampaipipatkul, "A study of content and training methods for a five-day trainercourse", master's thesis. Bangkok, Thailand: Mahidol University, 2004.

22. H. J. Klein, R. A. Noe, and C. Wang, "Motivation to learn and course outcomes: The impact of delivery mode, learning goal orientation, and perceived barriers and enablers", Personnel Psychology, vol. 59, 2006, pp. 665-702.

23. T. C. M. Lam, K. Kolomitro, and F. Alamparambil, "Empathy training: Methods, evalua-tion practices, and validity", Journal of MultiDisciplinary Evaluation, vol. 7 (16), 2011, pp. 162-200.

24. D.F. Barone, P.S. Hutchings, H.J. Kimmel, H.L. Traub, J.T. Cooper, and C.M. Marshall, "Increasing empathic accuracy through practice and feedback in a clinical interviewing course", Journal of Social \& Clinical Psychology, 24(2), 2005, pp. 156-171. 